\title{
Infant position in mother-calf dolphin pairs: formation locomotion with hydrodynamic benefits
}

\author{
S. R. Noren ${ }^{1, *}$, E. F. Edwards ${ }^{2}$ \\ ${ }^{1}$ Institute of Marine Science, University of California, Santa Cruz, Center for Ocean Health, 100 Shaffer Road, Santa Cruz, \\ California 95060, USA \\ ${ }^{2}$ Protected Resources Division, Southwest Fisheries Science Center, 3333 Torrey Pines Court, La Jolla, California 92037, USA
}

\begin{abstract}
Cetacean mother-calf dyads demonstrate formation locomotion that may provide hydrodynamic and/or social benefits. For example, echelon position (calf in close proximity of its mother's mid-lateral flank) enables calves to increase swim performance at reduced locomotor effort compared to periods of solitary swimming. Yet cetacean mother-calf dyads are also observed in infant position (calf in close proximity underneath its mother's tailstock), thus we wondered if infant positioning also provides hydrodynamic benefits to calves. Social and hydrodynamic benefits of infant position have both been hypothesized previously, but the logistical difficulties of conducting experiments on free-swimming mother-calf dolphin dyads have precluded empirical quantifications of kinematics until now. We demonstrated that 0 to $98 \mathrm{~d}$ old calves of the bottlenose dolphin Tursiops truncatus are afforded locomotor advantages while swimming in infant position with their mothers. Calves in infant position had reduced locomotor effort via a $24 \%$ reduction in fluke stroke amplitude compared to periods of solitary swimming. Yet stroke frequency (the other component of locomotor effort) and swim performance (swim speed) were not different between infant position and solitary swimming. Although swimming in infant position provided some hydrodynamic benefits to calves, these benefits paled in comparison to those afforded to calves maintaining echelon position. Given that echelon position provides the best hydrodynamic benefits, we speculate that older, stronger swimming calves are predominately in infant position because by relinquishing some hydrodynamic benefits of echelon position they gain important social benefits of infant position, particularly camouflage from predators, which undoubtedly plays a vital role in calf survival.
\end{abstract}

KEY WORDS: Cetaceans · Formation · Kinematics $\cdot$ Locomotion · Odontocetes · Swimming

\section{INTRODUCTION}

Formation locomotion is observed across diverse taxa in aerial, terrestrial, and aquatic environments and can provide social (i.e. Hamilton 1967, Pitcher et al. 1982) and/or energetic (i.e. Breder 1965, Lissaman \& Schollenberger 1970) advantages. Although applied to all modes of locomotion including walking (Fancy \& White 1985), saving energy by moving in formation is considered most practical in flying (Lissaman \& Schollenberger 1970, Hummel 1983) and swimming (Breder 1965, Weihs 1973). Energetic advantages are possible because animals set the fluid around them moving (air or water) and these fluid movements in some circumstances can be taken advantage of by another individual to decrease its energy cost of locomotion (for review see Alexander 2004). The energy savings of formation locomotion are predominately supported by theoretical work (i.e. Breder 1965, 1976 Belyayev \& Zuyev 1969, Lissaman \& Schollenberger 1970, Weihs 1973, 2004, Higdon \& Corrsin 1978, Badgerow \& Hainsworth 1981, Hummel 1983, 1995, Kshatriya \& Blake 1992) while empirical quantifications are rare. Only few studies have measured oxygen consumption rate (Parker 1973, Abrahams \& Colgan 1985, Fish 1994, Herskin \& Steffensen 1998), heart rate (Weimerskirch 
et al. 2001), and beat frequency of wing (Hainsworth 1987, Weimerskirch et al. 2001), leg (Fish 1995), or tail (Zuyev \& Belyayev 1970, Fields 1990, Fish et al. 1991, Herskin \& Steffensen 1998, Noren et al. 2008) for assessing reduced effort during formation locomotion.

Formation locomotion becomes particularly important when considering it as a form of calf carrying (Noren 2008). This is true for cetacean calves, who have extremely limited locomotor performance (Noren et al. 2006), yet at the same time must still maintain proximity to their mothers while she maneuvers within their habitat to forage and avoid predators. From the wild beluga whale Delphinapterus leucas (Krasnova et al. 2006) to the Southern right whale Eubaleana aus- tralis (Taber \& Thomas 1982) and captive and freeranging dolphins (McBride \& Kritzler 1951, Tavolga \& Essapian 1957, Norris \& Prescott 1961, Au \& Perryman 1982, Gubbins et al. 1999, Mann \& Smuts 1999), the predominant spatial states of mother-calf cetacean pairs are echelon position (calf in very close proximity to its mother's mid-lateral flank) and infant position (calf in very close positioning underneath its mother's tailstock; Fig. 1a, b) throughout the critical first year of development. The predominance of these positions has been suggested to have an adaptive significance that contributes to calf survival (Gubbins et al. 1999).

Indeed echelon position enables calves to achieve greater swimming speeds while also experiencing
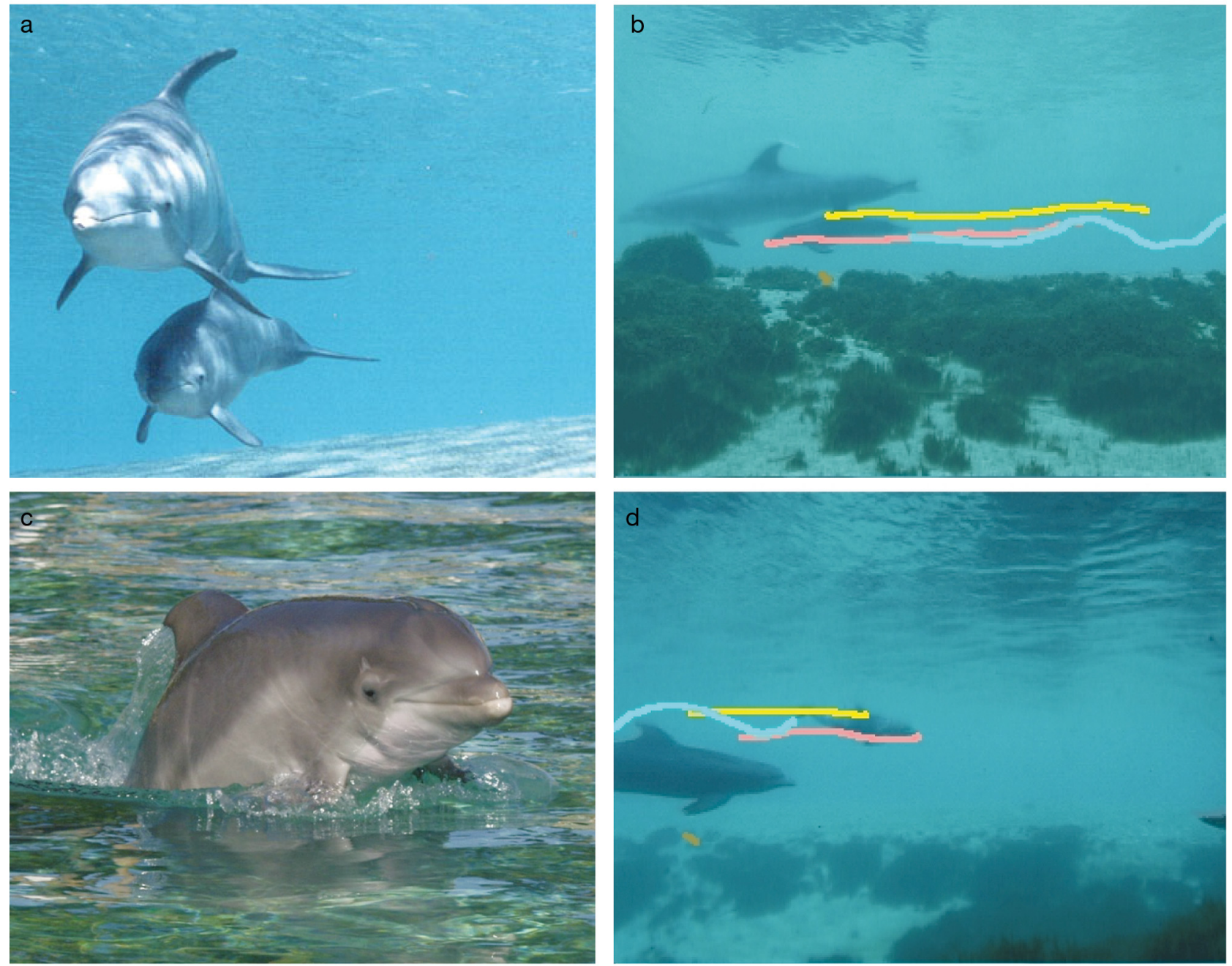

Fig. 1. Tursiops truncatus. Bottlenose dolphin calf swimming in $(\mathrm{a}, \mathrm{b})$ infant position with its mother and (c,d) solitarily. Infant position is described as calf swimming in very close positioning underneath its mother's peduncle (tailstock). Solitary swimming for the purpose of this study was defined as calf swimming $>1 \mathrm{~m}$ from all other dolphins. (b,d) Tracings from digitized video clips. Anatomical points of interest (rostrum tip $=$ pink, cranial insertion of the dorsal fin = yellow, and fluke tip = blue) were digitized at a rate of 60 fields per second of video using a motion-analysis system (Peak Motus 6.1, Peak Performance Technologies) following Noren et al. $(2006,2008)$ and Noren (2008). A distinct trace represents the movements of each digitized anatomical point. The brown dot is a digitized reference point indicating that the camera was steady during filming. Photo for a and $\mathrm{c}$ provided by Dolphin Quest 
reduced locomotor effort in the form of glide periods, reduced stroke amplitude, and increased distance per stroke; thus there are clear hydrodynamic benefits for calves in echelon position (Noren et al. 2008). However, as cetacean offspring increase in size, there is an increase in the active prevention and/or avoidance of echelon positioning by mothers (Taber \& Thomas 1982, Mann \& Smuts 1999), such that with age, there is a decrease in the time cetacean calves swim in echelon (Taber \& Thomas 1982, Mann \& Smuts 1999). It has been suggested that as calves grow and begin to approximate their mother's body size, they become too large to fully benefit from an echelon swimming position (Weihs 2004). The maternal avoidance of echelon position might also represent a parent-offspring conflict (Trivers 1974), because mothers that swim in echelon position with their calves experience increased swim effort and reduced swim performance compared to periods of solitary swimming (Noren 2008). This might explain the change in predominant spatial state away from echelon position and towards infant position as calves develop and grow. For example, based on observations of wild dolphins, the frequency of echelon position decreased from 69 to $11 \%$ from 1 to 2 mo postpartum, while infant position became increasingly important from 8 to $18 \%$ (Mann \& Smuts 1999). Observations of captive dolphins show similar trends: The frequency of echelon position decreased from 67 to $23 \%$ over the first year postpartum, while infant position increased from 7 to $38 \%$ (Gubbins et al. 1999). Yet undeveloped physiology combined with diminutive body size act synergistically to limit swim performance capabilities for dolphins for the entire first year of life (Noren et al. 2006), thus we wondered if infant position provides hydrodynamic benefits to calves.

This study aimed to elucidate empirically the hydrodynamic benefits gained by calves maintaining infant position by examining the kinematics of calves of the bottlenose dolphin Tursiops truncatus swimming in infant position and comparing that to periods during which the calves swam independently of their mothers (>1 m from all other dolphins; Fig. 1c,d). Because the morphology and swimming kinematics of dolphins are characteristic of the thunniform mode, which is typical of some of the fastest marine vertebrates (including scombrid fishes, laminid sharks, and cetaceans; Lighthill 1969), dolphins generate thrust exclusively with a high aspect-ratio caudal hydrofoil (tailflukes; Fish \& Hui 1991). Thus, a qualitative assessment of swim effort was obtained by considering the quantitative measurements of tail movement amplitude and beat frequency; higher amplitudes and frequencies are associated with greater energy expenditure (Kooyman \& Ponganis 1998). Swim performance was also examined quantitatively by comparing swim speeds.

\section{MATERIALS AND METHODS}

Three captive bottlenose dolphin mother-calf pairs provided a controlled experimental approach to investigate cetacean locomotor effort and performance (Fish 1993, Skrovan et al. 1999, Noren et al. 2006). A stationary submerged SCUBA diver with a digital video camcorder (Hi-8, Sony) in an underwater housing (Amphibico Dive Buddy, Amphibico) videotaped dolphins swimming in a large natural lagoon $(43 \times 53 \mathrm{~m}, 7 \mathrm{~m}$ deep) at Dolphin Quest Hawaii during daylight hours. The animals swam 0.5 to $1.0 \mathrm{~m}$ below the surface of the water and swam within 7 to $8 \mathrm{~m}$ in front of the SCUBA diver. All experimental swim sessions were opportunistic (no reward). Videotape of infant position (Fig. 1a,b) and calf swimming solitarily (Fig. 1c,d) was acquired when the calves were 0 to $98 \mathrm{~d}$ postpartum (October 2003 to January 2004). We recorded $19 \mathrm{~h}$ of swimming. Short 1 to $6 \mathrm{~s}$ video clips in which dolphins were stroking and swimming steadily, maintained a parallel path to the camera lens, and had no qualitatively apparent acceleration were extracted from the videotapes using digital video software (Pinnacle Studio 8, Pinnacle Systems; Fig. 1b,d). The resulting 209 video clips were divided into 2 association categories: (1) infant position (calf in very close positioning underneath mother's peduncle (tailstock); Fig. 1a,b) and (2) solitary swimming (calf $>1 \mathrm{~m}$ away from all dolphins; Fig. 1c,d). A quantitative assessment of the kinematics of infant position and solitary swimming was obtained by calculating both peak-to-peak fluke stroke amplitude and tailbeat oscillation frequency; this provided the foundation for our qualitative assessment of swim effort. Normalized tailbeat frequency (ratio of tailbeat frequency to swim speed; Rohr \& Fish 2004) and distance per stroke were also calculated. A quantitative assessment of swim performance was possible by comparing swim speeds across swimming behaviors (infant position and solitary). Additional information regarding the methods for video analysis and swim effort calculations are described in detail in Noren et al. (2006).

The goal of this study was to quantify changes in locomotor performance associated with swimming behavior (infant position versus solitary), thus data across individuals were combined. Each data point was obtained from a unique trial (a complete pass of the animal past the video camera), and each trial was of a slightly different swim speed, thus measurements were considered independent as has been done previously in similar studies (Fish 1993, Skrovan et al. 1999, Noren et al. 2006, 2008, Noren 2008). The calf ages and swim speeds that comprised each swimming category were compared using Mann-Whitney rank sum test (test statistic: $T$ ) and Student's $t$-test (test statistic: $t$ ), 
respectively. Least squares linear regression analyses were used to determine the relationships for speed versus peak-to-peak stroke amplitude and speed versus tailbeat oscillation frequency for each swimming behavior; the significance of the regressions was determined using F-tests. Age and the resulting change in body size influence swimming capabilities of immature solitary dolphins (Noren et al. 2006), but it is unknown how age and the resulting change in body size influence the swimming capabilities of dolphins in infant position. Therefore, age versus swim speed, stroke amplitude, normalized stroke frequency, and distance per stroke were determined separately for each swimming behavior (infant position or solitary) by least squares linear regression analyses; the significance of the regressions was determined using $F$-tests. In cases where the swimming kinematic was significantly correlated with age, the slopes and intercepts across swimming behaviors (infant position and solitary) were compared by Student's t-tests. Statistical analyses were performed using Sigma Stat 2.03 (Systat Software). Means $\pm 1 \mathrm{SE}$. are presented, and $\alpha=0.05$ was used for all statistical analyses.

\section{RESULTS}

The ages that comprised the infant position category (range: 5 to $96 \mathrm{~d}$, median $=22 \mathrm{~d}$, mean $=31 \pm 3 \mathrm{~d}, \mathrm{n}=$ 61) were similar ( $T=6241.50, p=0.68)$ to those that comprised the solitary swimming category (range: 0 to $98 \mathrm{~d}$, median $=24 \mathrm{~d}$, mean $=35 \pm 2 \mathrm{~d}, \mathrm{n}=148$ ). In addition, swim speeds for infant position trials (range: 0.74 to $2.81 \mathrm{~m} \mathrm{~s}^{-1}$, median $=1.32 \mathrm{~m} \mathrm{~s}^{-1}$, mean $=1.47 \pm$ $\left.0.06 \mathrm{~m} \mathrm{~s}^{-1}, \mathrm{n}=61\right)$ were similar $(t=1.65, \mathrm{df}=207, \mathrm{p}=$ $0.10)$ to those representing solitary swimming trials (range: 0.62 to $4.20 \mathrm{~m} \mathrm{~s}^{-1}$, median $=1.53 \mathrm{~m} \mathrm{~s}^{-1}$, mean $=$ $\left.1.62 \pm 0.05 \mathrm{~m} \mathrm{~s}^{-1}, \mathrm{n}=148\right)$. Stroke frequency was correlated with speed for both infant position swimming $(\mathrm{r}=$ $0.68, F=50.42, \mathrm{p}<0.0001)$ and solitary swimming $(\mathrm{r}=$ 0.67, $F=116.70, \mathrm{p}<0.0001$ ) (Fig. 2a). In contrast, stroke amplitude was not related with swim speed for either infant position swimming $(\mathrm{r}=0.04, F=0.101, \mathrm{p}=$ $0.75, \mathrm{n}=61)$ or solitary swimming $(\mathrm{r}=0.06, F=0.479$, $\mathrm{p}=0.49, \mathrm{n}=148)$ (Fig. 2b); this result is consistent with what has previously been described for adult odontocetes, which do not modulate swim speed by changing stroke amplitude (Fish 1993, Skrovan et al. 1999, Fish et al. 2003). Indeed, analyses of the product of stroke frequency and stroke amplitude in relation to speed for both infant position swimming $(\mathrm{r}=0.50, F=19.672$, $\mathrm{p}<$ $0.001, \mathrm{n}=61)$ and solitary swimming $(\mathrm{r}=0.61, F=$ 84.137, $\mathrm{p}<0.001, \mathrm{n}=148$ ) revealed that the inclusion of stroke amplitude does not improve the predictive power for speed as has been found previously for fish
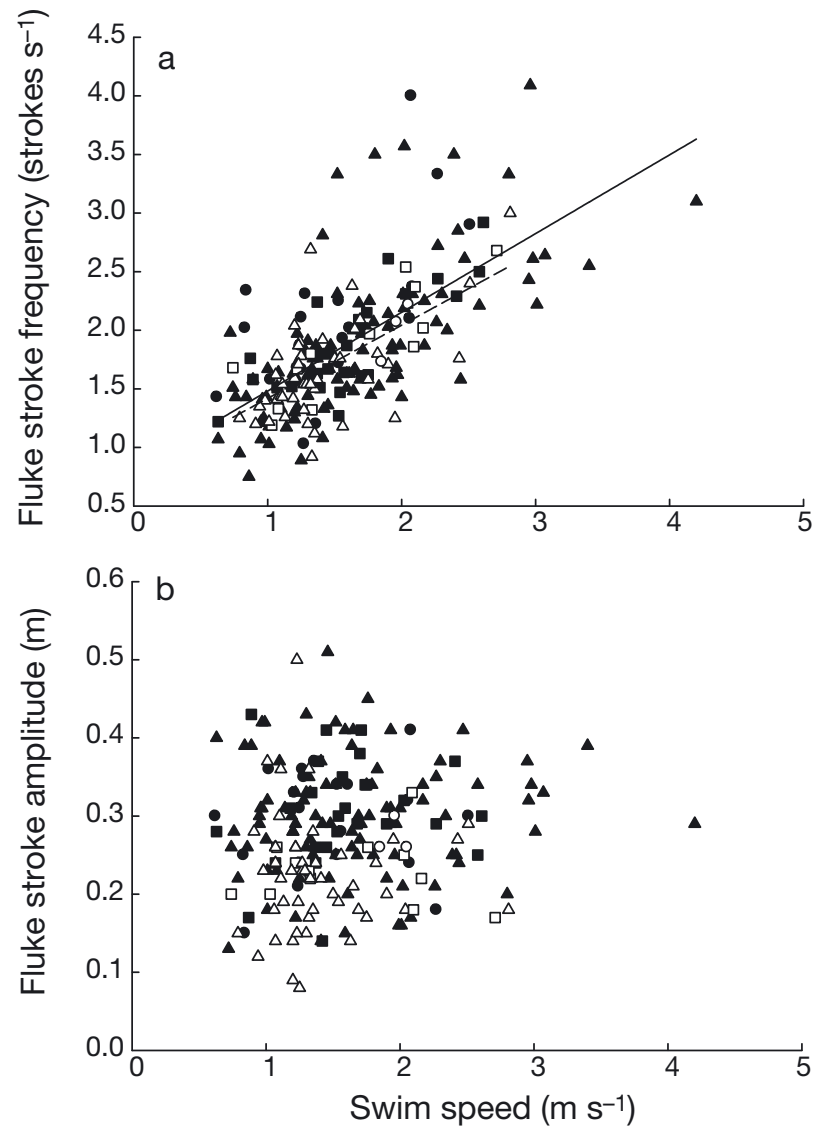

Fig. 2. Tursiops truncatus. (a) Fluke stroke frequency (strokes $\mathrm{s}^{-1}$ ) and (b) stroke amplitude $(\mathrm{m})$ in relation to swim speed (m $\mathrm{s}^{-1}$ ) for 3 individual bottlenose dolphin calves swimming in infant position $(\Delta, \square, O)$ or solitarily $(\boldsymbol{\Lambda}, \mathbf{\square}, \boldsymbol{\Theta})$. Stroke frequency was correlated with swim speed for both infant position swimming $($ Swim Speed $=0.62 \times$ Stroke Frequency + $0.79 ; \mathrm{n}=61$; dashed line) and solitary swimming (Swim Speed $=0.67 \times$ Stroke Frequency $+0.81 ; \mathrm{n}=148$; solid line). Stroke amplitude was not correlated with swim speed for either infant position or solitary swimming (see Results for statistics)

(Webb 1973, 1993), but rather the inclusion of stroke amplitude lowers the correlation value (r) due to the increased scatter. This result is likely due to the fact that, as found for fish, modulation of both stroke frequency and stroke amplitude to affect swim speed is prevalent only at lower speeds (i.e. Bainbridge 1958, Webb 1975) as stroke amplitude reaches its maximum ( $\sim .2$ body lengths) at higher speeds (Bainbridge 1958). In this study, the majority of trials were from dolphins swimming $>1 \mathrm{~m} \mathrm{~s}^{-1}$, and size-specific stroke amplitudes clustered around 0.2 body lengths (infant: mean $\pm \mathrm{SD}=0.18 \pm 0.006$ body lengths, median $=$ 0.18 body lengths; solitary: mean $\pm \mathrm{SD}=0.24 \pm 0.004$ body lengths, median $=0.24$ body length). This suggests that these individuals were near their maximum size-specific stroke amplitude when swimming in 
infant position and at their maximum size-specific stroke amplitude when swimming solitarily.

Age was related to swim speed (Fig. 3a), normalized stroke frequency, distance per stroke (Fig. 3b), and fluke stroke amplitude (Fig. 3c) for 0 to $98 \mathrm{~d}$ old dolphins swimming in infant position and solitarily (see Table 1 for statistics). Thus for subsequent analyses, the slopes and intercepts for the relationships for age and these kinematic variables were compared across swimming categories. The relationships for age versus swim speed, normalized stroke frequency, and distance per stroke were not different between infant position and solitary swimming (see Table 1 for statistics). Although the slopes for age versus fluke stroke amplitude were similar across swimming categories, the y-intercept for infant position swimming was significantly lower than that for solitary swimming (see Table 1 for statistics) indicating that calves in infant position maintain lower stroke amplitudes compared to calves swimming solitarily. Indeed, mean fluke stroke amplitude of calves in infant position $(0.23 \pm 0.01 \mathrm{~m})$ was significantly lower $(t=6.69, \mathrm{df}=207, \mathrm{p}<0.001)$ than mean stroke amplitudes during solitary swimming $(0.30 \pm 0.01 \mathrm{~m})$. Infant position swimming enabled 0 to $98 \mathrm{~d}$ old calves to decrease their stroke amplitude by $24 \%$ compared to periods of solitary swimming.

\section{DISCUSSION}

Formation locomotion is an important strategy that ensures that cetacean mother-calf dyads remain intact during travel, which is vital to the survival of the offspring. Without the energetic advantages of formation locomotion independently swimming bottlenose dolphin calves are unable to achieve swim performance levels similar to those of adults, as average and maximum swim speeds of 0 to 1 mo old calves are only 37 and $52 \%$ of that for adults, respectively (Noren et al. 2006). During this period of development, echelon is the predominant spatial state of mother-calf dolphin pairs, and this formation provides significant hydrodynamic benefits to the calf (Noren et al. 2008). Yet average and maximum swim performance levels of dolphin calves at 3 mo postpartum still remain dramatically lower than adult levels, representing only $50 \%$ of adult performance (calculated from Noren et al. 2006), and the swim performance of calves throughout the first year of life remains
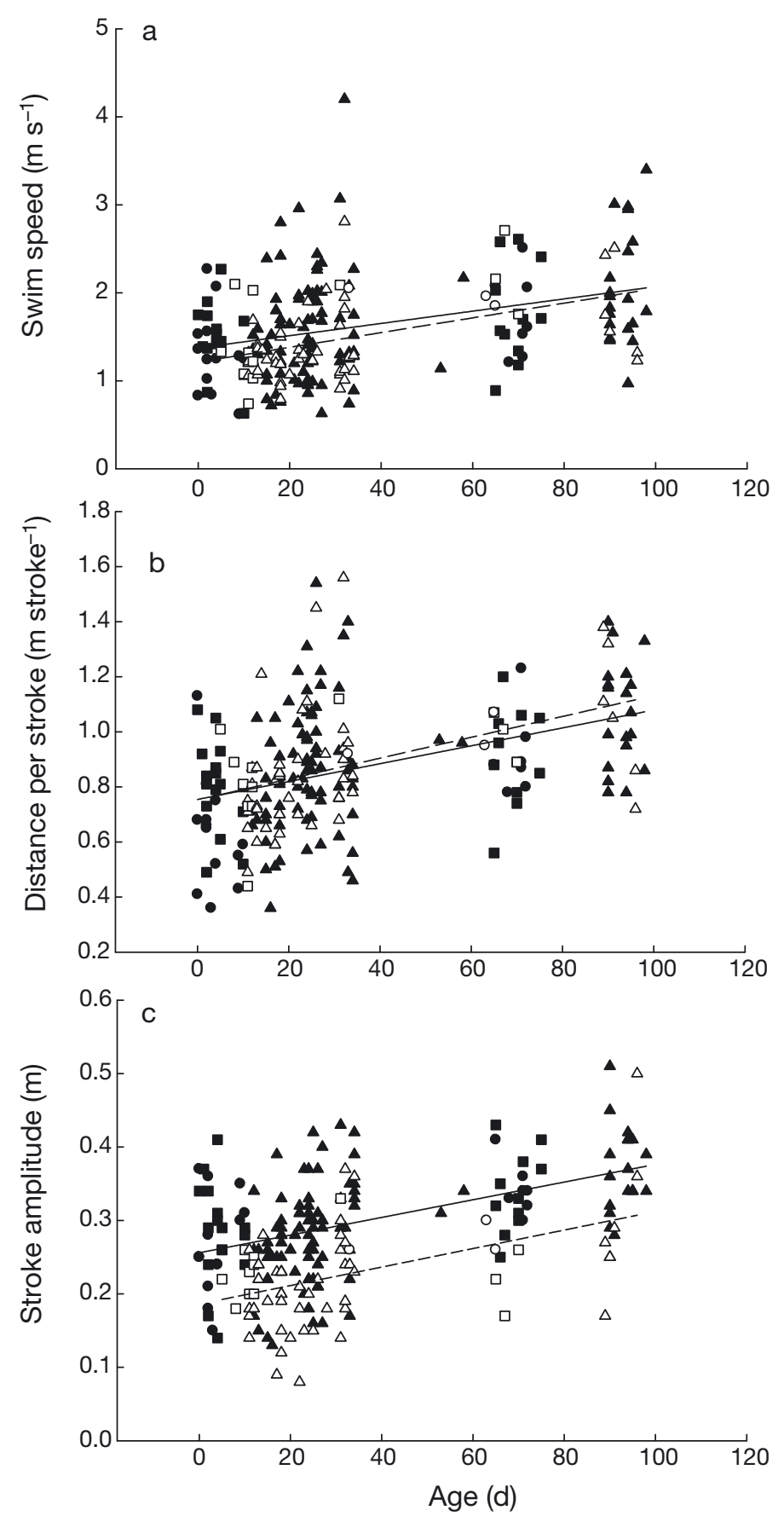

Fig. 3. Tursiops truncatus. (a) Swim speed $\left(\mathrm{m} \mathrm{s}^{-1}\right)$, (b) distance per stroke $\left(\mathrm{m}\right.$ stroke $\left.\mathrm{e}^{-1}\right)$, and (c) fluke stroke amplitude $(\mathrm{m})$ in relation to age (d) for 3 individual bottlenose dolphin calves swimming in infant position $(\Delta, \square, \bigcirc)$ and solitarily $(\boldsymbol{\Lambda}, \mathbf{\square}, \mathbf{0})$. Swim speed was correlated with age for both infant position (Swim Speed $=0.008 \times$ Age $+1.21 ; n=$ 61; dashed line) and solitary (Swim Speed $=0.007 \times$ Age $+1.37 ; \mathrm{n}=$ 148 ; solid line) swimming. Distance per stroke was correlated with age for both infant position swimming (Distance per Stroke $=0.004 \times$ Age $+0.75 ; \mathrm{n}=61$; dashed line) and solitary swimming (Distance per Stroke $=0.003 \times$ Age $+0.75 ; \mathrm{n}=148 ;$ solid line). Stroke amplitude was correlated with age for both infant position swimming (Stroke Amplitude $=0.001 \times$ Age $+0.19 ; \mathrm{n}=61$; dashed line) and solitary swimming $($ Stroke Amplitude $=0.001 \times$ Age $+0.26 ; \mathrm{n}=148$; solid line $)$. See Table 1 for statistics 
Table 1. Tursiops truncatus. Statistical results for the relationships of age to swim speed, normalized stroke frequency, distance per stroke, and stroke amplitude for infant position and solitary swimming. Statistics for the comparison of slopes and y-intercepts across infant position and solitary swimming are also provided

\begin{tabular}{|c|c|c|c|c|c|c|c|c|c|c|c|c|}
\hline & \multicolumn{3}{|c|}{ Solitary swimming } & \multicolumn{3}{|c|}{ Infant swimming } & \multicolumn{3}{|c|}{ Slope comparison } & \multicolumn{3}{|c|}{ Intercept comparison } \\
\hline & $\mathrm{r}$ & $F$ & $\mathrm{p}$ & $\mathrm{r}$ & $F$ & $\mathrm{p}$ & $t$ & $\mathrm{df}$ & $\mathrm{p}$ & $t$ & $\mathrm{df}$ & $\mathrm{p}$ \\
\hline Age vs. Swim Speed (Fig. 3a) & 0.35 & 19.87 & $<0.0001$ & 0.45 & 14.77 & 0.0003 & -0.49 & 207 & 0.63 & 1.28 & 207 & 0.200 \\
\hline Age vs. Normalized Stroke Frequency & 0.39 & 26.75 & $<0.0001$ & 0.43 & 13.08 & 0.0006 & 0.00 & 207 & 1.00 & 0.62 & 207 & 0.540 \\
\hline Age vs. Distance per Stroke (Fig. 3b) & 0.43 & 32.31 & $<0.0001$ & 0.44 & 13.90 & 0.0004 & -0.53 & 207 & 0.60 & 0.03 & 207 & 0.980 \\
\hline Age vs. Stroke Amplitude (Fig. 3c) & 0.50 & 49.33 & $<0.0001$ & 0.45 & 14.96 & 0.0003 & 0.27 & 207 & 0.79 & 4.70 & 207 & 0.001 \\
\hline
\end{tabular}

significantly lower than adult levels (Noren et al. 2006). During these later stages of development, infant position becomes the predominant spatial state, thus we wondered if calves in infant position gain hydrodynamic benefits.

Through kinematic analyses this study demonstrates empirically that 0 to $98 \mathrm{~d}$ old bottlenose dolphin calves in infant position are afforded some locomotor advantages. Calves in infant position had reduced swim effort via a $24 \%$ reduction in fluke stroke amplitude compared to periods of solitary swimming. Given that the stroking of the flukes of the mother-calf pairs in infant position was consistently unsynchronized, the reduced stroke amplitudes of calves in infant position may be due to a mechanical constraint as the calves attempted to avoid contact with their mother's peduncle. Indeed, only $24 \%$ of the video clips examined in this study showed peduncle or fluke bumping between the 2 animals, and in these cases, the bumping seemed to be intentional by the mother because after she bumped her calf she immediately rolled to her side to present her mammary slits. Regardless of the reason for the reduced stroke amplitude, the lowered stroke amplitude is associated with decreased energy expenditure (Kooyman \& Ponganis 1998), and this result is consistent with other modes of formation swimming. Both dolphin calves in echelon position (Noren et al. 2008) and paddling ducklings in ' $\mathrm{V}$ ' formation (Fish 1995) have reduced stroke amplitude compared to periods of solitary locomotion. Meanwhile, swim speed and distance per stroke for calves in infant position did not appear to differ from levels achieved during periods of solitary swimming (Fig. 3b). This result is different from that found for calves swimming in echelon position, which benefited from increased distance per stroke and enhanced swim speed (Noren et al. 2008).

The empirical study of Noren et al. (2008) and the present study confirm the theoretical models of Weihs (2004), which predicted that echelon and infant position both provide hydrodynamic boosts to calves, with echelon position affording the greatest hydrodynamic benefits. Weihs (2004) attributed the hydrodynamic advantages for calves in echelon position to the Bernoulli effect: The flow on the side of the mother's body closer to the calf moves faster and produces a pressure drop that leads to a suction force 'pulling' the calf to the mother. Meanwhile, Weihs (2004) identified smaller gains afforded to calves in infant position, because the dominant force facilitating calves in this position is the forward momentum they gain from the boundary layer shed by the mother. As the mother moves forward, water behind the body moves forward to replace the animal's mass, giving the calf a hydrodynamic boost in the forward-moving areas. Indeed, the swimming kinematic data of 0 to $34 \mathrm{~d}$ old calves in echelon position and 0 to $34 \mathrm{~d}$ old calves in infant position (data from Noren et al. 2008 and present study) show that although stroke amplitude was similar across these positions $(t=-0.13$, df $=211$, $\mathrm{p}=0.90)$, calves achieved greater distance per stroke $(T=$ 4001.50, 163, $\mathrm{p}<0.001, \mathrm{n}=50$ ) and greater swim speed $(T=3959.50, \mathrm{p}<0.001, \mathrm{n}=50,163)$ in echelon position compared to infant position. Regardless, dolphin calves in echelon and infant positions, like ducklings in ' $\mathrm{V}$ ' formation, extract energy from environmental vortices that arise from fluid flow from the propulsive movements of other individuals (Kelly 1959, Weihs 2004).

An understanding of the developmental physiology of dolphins offers insight into why the hydrodynamic benefits afforded to calves in formation locomotion remain important for the first year after birth. Immature dolphins have lower aerobic and anaerobic capacities in the muscle (reviewed by Noren \& Edwards 2007) and proportionally smaller muscle mass (reviewed by McLellan et al. 2002) than adult conspecifics. At the same time, extreme skeletal and muscular flexibility (Etnier et al. 2004) and floppy (hydrodynamically ineffective) dorsal fins and flukes (McBride \& Kritzler 1951, Tavolga \& Essapian 1957, Cockcroft \& Ross 1990) compromise the swimming efficiency of newborns, while small body size throughout ontogeny limits swimming performance as swimming speed is proportionate to body size across cetaceans (Fish 1998). Underdeveloped physiology correlates with the reduced swim performance of calves $<1$ yr postpartum (Noren et al. 2006). Given that swim performance is reduced for the entire first year of life, it seems counterintuitive that calves switch from 
echelon to infant position by 2 mo postpartum and by doing so relinquish some hydrodynamic benefits.

It has been hypothesized that infant position, unlike echelon position, serves social functions. Gubbins et al. (1999) proposed that infant position (1) may offer protection from predators, (2) may facilitate nursing, (3) may be due to phylogenetic constraint, since closely related ungulate mothers keep their offspring underneath the rear of their body, or (4) may provide some social significance since calves assume this position when they are startled or tired. Some of these hypotheses seem less compelling than others. For example, infant position does not always lead to nursing (Gubbins et al. 1999, S. R. Noren pers. obs.), and the frequency of nursing decreases after 1 mo postpartum (reviewed by Mello et al. 2005), while the frequency of infant position increases (Gubbins et al. 1999, Mann \& Smuts 1999). In addition, infant position is not simply a homologous trait with ungulates, because there are hydrodynamic benefits afforded to calves that maintain this position (Weihs 2004, present study). Thus, the most compelling social benefit of infant position is protection from predators: When viewed from below (common perspective for sharks attacking dolphins) the white ventral surface of the calf in infant position blends with the white of the mother's underside and the bright water surface, making the mother-calf pair appear as one large animal (Gubbins et al. 1999). Furthermore, the observation that a calf assumes infant position when it is startled or tired (Gubbins et al. 1999) may also be related to predator avoidance. Dolphins, like grazers in African savannas, are reliant on speed for survival because they inhabit open environments that do not offer refuges from predators. Thus, when a predatory threat is perceived it is advantageous for the calf to assume a position that provides both camouflage and hydrodynamic benefits for fleeing. Indeed, during travel, dolphin calves are observed swimming in infant position (Mann \& Smuts 1999). Thus by 3 to 6 mo postpartum, when dolphin calves have some improvement in swimming (Noren et al. 2008) and breath-holding (Noren et al. 2002) — both capabilities that improve the maintenance of infant position - the benefit of predatory avoidance gained in infant position likely outweighs the cost of losing the enhanced hydrodynamic benefits of echelon position.

In summary, we provide the first empirical quantification of hydrodynamic benefits gained by cetacean calves that maintain infant position. Through kinematic analyses, we demonstrate that calves in infant position are afforded reduced swim effort through lowered fluke stroke amplitudes compared to periods of solitary swimming. Although the hydrodynamic benefits gained in this position pale in comparison to those gained by calves in echelon position, calves in infant position are likely afforded other advantages, such as camouflage from predators. A future direction of study is to investigate the potential hydrodynamic costs incurred by mothers traveling with calves in infant position because the entrained calf could increase drag and disrupt the boundary flow around the mother. To compensate, the mother may need to generate greater power output per a given speed which could decrease her swimming performance as has been shown for mothers traveling with calves in echelon position (Noren 2008).

Acknowledgements. We thank the lab group of T. Williams of the University of California Santa Cruz (UCSC), and J. Redfern and N. Kellar of Southwest Fisheries Science Center (SWFSC) for insightful comments on earlier drafts of this manuscript. We are particularly thankful to Dolphin Quest, especially J. Sweeney and R. Stone, for providing animals and partial funding for this study. This project would not have been possible without additional financial support from the Protected Resources Division at SWFSC. We also thank the staff at Dolphin Quest Hawaii (particularly C. Buczyna) for their assistance during data collection, T. Williams of UCSC for the use of her Peak Motus system, J. Redfern of SWFSC for assistance with data management, and E. Ryan for data entry.

\section{LITERATURE CITED}

Abrahams MV, Colgan PW (1985) Risk of predation, hydrodynamic efficiency and their influence on school structure. Environ Biol Fishes 13:195-202

Alexander RM (2004) Hitching a lift hydrodynamically — in swimming, flying, and cycling. J Biol 3:7

$\mathrm{Au}$ D, Perryman W (1982) Movement and speed of dolphin schools responding to an approaching ship. Fish Bull 80: 371-379

Badgerow JP, Hainsworth FR (1981) Energy savings through formation flight? A re-examination of the vee formation. J Theor Biol 93:41-52

Bainbridge R (1958) The speed of swimming fish as related to size and to the frequency and amplitude of the tail beat. J Exp Biol 35:109-133

Belyayev VV, Zuyev GV (1969) Hydrodynamic hypothesis of schooling in fishes. J Ichthyol 9:578-584

Breder CM Jr (1965) Vortices of fish schools. Zoologica (N.Y.) 50: $97-114$

Breder CM Jr (1976) Fish schools as operational structures. Fish Bull 74:471-502

Cockcroft VG, Ross GJB (1990) Observations on the early development of a captive bottlenose dolphin calf. In: Leatherwood S, Reeves RR (eds) The bottlenose dolphin. Academic Press, New York, NY, p 461-478

Etnier SA, Dearolf JL, McLellan WA, Pabst DA (2004) Postural role of lateral axial muscles in developing bottlenose dolphins (Tursiops truncatus). Proc R Soc Lond, B 271: 909-918

Fancy SG, White RG (1985) Incremental cost of activity. In: Hudson RJ, White RG (eds) Bioenergetics of wild herbivores. CRC Press, Boca Raton, FL, p 143-159

Fields PA (1990) Decreased swimming effort in groups of Pacific mackerel (Scomber japanicus). Am Zool 30:134A

Fish FE (1993) Power output and propulsive efficiency of swimming bottlenose dolphins (Tursiops truncatus). J Exp Biol 185:179-193

Fish FE (1994) Energy conservation by formation swimming: metabolic evidence from ducklings. In: Maddock L, Bone 
Q, Rayner JMV (eds) Mechanics and physiology of animal swimming. Cambridge University Press, Cambridge, p 193-204

Fish FE (1995) Kinematics of ducklings swimming in formation: consequences of position. J Exp Zool 273:1-11

Fish FE (1998) Comparative kinematics and hydrodynamics of odontocete cetaceans: morphological and ecological correlates with swimming performance. J Theor Biol 201: 2867-2877

Fish FE, Hui CA (1991) Dolphin swimming — a review. Mammal Rev 21:181-195

Fish FE, Fegely JF, Xanthopoulos CJ (1991) Burst-and-coast swimming in schooling fish (Notemigonus crysoleucas) with implications for energy economy. Comp Biochem Physiol A 100:633-637

Fish FE, Peacock JE, Rohr JJ (2003) Stabilization mechanism in swimming odontocete cetaceans by phased movements. Mar Mamm Sci 19:515-528

Gubbins C, McCowan B, Lynn SK, Hooper S, Reiss D (1999) Mother-infant spatial relations in captive bottlenose dolphins, Tursiops truncatus. Mar Mamm Sci 15:751-765

Hainsworth FR (1987) Precision and dynamics of positioning by Canada geese flying formation. J Exp Biol 128:445-462

Hamilton WJ III (1967) Social aspects of bird orientation mechanisms. In: Stone RM (ed) Animal orientation and navigation. Oregon State University Press, Corvallis, OR, p $57-71$

Herskin J, Steffensen JF (1998) Energy savings in sea bass swimming in a school: measurements of tail beat frequency and oxygen consumption at different swimming speeds. J Fish Biol 53:366-376

Higdon JJL, Corrsin S (1978) Induced drag of a bird flock. Am Nat 112:727-744

Hummel D (1983) Aerodynamic aspects of formation flight in birds. J Theor Biol 104:321-347

Hummel D (1995) Formation flight as an energy saving mechanism. Isr J Zool 41:261-278

Kelly HR (1959) A two body problem in the echelon swimming of porpoise. Naval Ordinance Test Station Technical Note 40606-1

Kooyman GL, Ponganis PJ (1998) The physiological basis for diving at depth: birds and mammals. Annu Rev Physiol 60:19-32

Krasnova VV, Bel'kovick VM, Chernetsky AD (2006) Motherinfant spatial relations in wild beluga (Delphinapterus leucas) during postnatal development under natural conditions. Biol Bull 33:53-58

Kshatriya M, Blake RW (1992) Theoretical model of the optimum flock size of birds flying in formation. $\mathrm{J}$ Theor Biol 157:135-174

Lighthill MJ (1969) Hydrodynamics of aquatic animal propulsion. Annu Rev Fluid Mech 1:413-446

Lissaman PBS, Schollenberger C (1970) Formation flight in birds. J Theor Biol 104:321-347

Mann J, Smuts B (1999) Behavioral development in wild bottlenose dolphin newborns (Tursiops sp.). Behaviour 136:529-566

McBride AF, Kritzler H (1951) Observations on pregnancy, parturition, and post-natal behavior in the bottlenose dolphin. J Mammal 32:251-266

McLellan WA, Koopman HN, Rommel SA, Read AJ, Potter CW, Nicolas JR, Westgate AJ, Pabst DA (2002) Ontogenetic allometry and body composition of harbour porpoises (Phocoena phocoena, L.) from the western North

Editorial responsibility: Michael Castellini,

Fairbanks, Alaska, USA
Atlantic. J Zool (Lond) 257:457-471

Mello I, Nordensten L, Amundin M (2005) Reactions of three bottlenose dolphin dams with calves to other members of the group in connection with nursing. Zoo Biol 24:543-555

Noren SR (2008) Infant carrying behavior in dolphins: costly parental care in an aquatic environment. Funct Ecol 22: 284-288

> Noren SR, Edwards EF (2007) Physiological and behavioral development in dolphin calves: implications for calf separation and mortality due to tuna purse-seine sets. Mar Mamm Sci 23:15-29

Noren SR, Lacave GL, Wells RS, Williams TM (2002) The development of blood oxygen stores in bottlenose dolphins (Tursiops truncatus): implications for diving capacity. J Zool 258:105-113

Noren SR, Biedenbach G, Edwards EF (2006) The ontogeny of swim performance and mechanics in bottlenose dolphins (Tursiops truncatus). J Exp Biol 209:4724-4731

> Noren SR, Biedenbach G, Redfern JV, Edwards EF (2008) Hitching a ride: the formation locomotion strategy of dolphin calves. Funct Ecol 22:278-283

Norris KS, Prescott JH (1961) Observations on Pacific cetaceans of Californian and Mexican waters. Univ Calif Publ Zool 63:291-402

Parker FR Jr (1973) Reduced metabolic rates in fishes as a result of induced schooling. Trans Am Fish Soc 102: $125-130$

Pitcher TJ, Magurran AE, Winfield IJ (1982) Fish in larger shoals find food faster. Behav Ecol Sociobiol 10:149-151

Rohr JJ, Fish FE (2004) Strouhal numbers and optimization of swimming by odontocete cetaceans. J Exp Biol 207: 1633-1642

> Skrovan RC, Williams TM, Berry PS, Moore PW (1999) The diving physiology of bottlenose dolphins (Tursiops truncatus) II. Biomechanics and changes in buoyancy at depth. J Exp Biol 202:2749-2761

> Taber S, Thomas P (1982) Calf development and mother-calf spatial relationships in Southern right whales. Anim Behav 30:1072-1083

Tavolga MC, Essapian FS (1957) The behavior of the bottlenosed dolphin (Tursiops truncatus): mating, pregnancy, parturition and mother-infant behavior. Zoologica (N.Y.) 42: $11-31$

Trivers R (1974) Parent-offspring conflict. Am Zool 14: 249-264

Webb PW (1973) Effects of partial caudal-fin amputation on the kinematics and metabolic rate of underyearling sockeye salmon (Oncorhynchus nerka) at steady swimming speeds. J Exp Biol 59:565-581

Webb P (1975) Hydrodynamics and energetics of fish propulsion. Bull Fish Res Board Can 190:1-158

Webb PW (1993) The effect of solid and porous channel walls on steady swimming of steelhead trout Oncorhynchus mykiss). J Exp Biol 178:97-108

Weihs D (1973) Hydrodynamics of fish schooling. Nature 241:290-291

Weihs D (2004) The hydrodynamics of dolphin drafting. J Biol 3:8

Weimerskirch H, Martin J, Clerquin Y, Alexander $\mathrm{P}$, Jiraskova S (2001) Energy saving in flight formation. Nature 413:697-698

Zuyev GV, Belyayev VV (1970) An experimental study of fish in groups as exemplified by the horse mackerel (Trachurus mediterraneus ponticus Aleev). J Ichthyol 10:546-549

Submitted: August 11, 2010; Accepted: December 9, 2010

Proofs received from author(s): February 19, 2011 